\title{
Elephants in Africa: Big, grey biodiversity thieves?
}

AUTHORS:

Timothy R. Kuiper ${ }^{1}$

Daniel M. Parker ${ }^{1}$

\section{AFFILIATION:}

${ }^{1}$ Wildlife and Reserve

Management Research Group,

Department of Zoology and

Entomology, Rhodes University,

Grahamstown, South Africa

\section{CORRESPONDENCE TO:}

Timothy Kuiper

EMAIL:

timothykuiper@gmail.com

\section{POSTAL ADDRESS:}

Wildlife and Reserve

Management Research Group,

Department of Zoology and

Entomology, Rhodes University,

P0 Box 94, Grahamstown 6140,

South Africa

\section{KEYWORDS:}

conservation; ecosystem change; habitat heterogeneity; large herbivores; Africa

\section{HOW TO CITE:}

Kuiper TR, Parker DM.

Elephants in Africa: Big, grey biodiversity thieves? S Afr J Sci. 2014;110(3/4), Art. \#a0058, 3 pages. http://dx.doi.org/10.1590/ sajs.2014/a0058

(C) 2014. The Authors. Published under a Creative Commons Attribution Licence.

\section{At the outset}

The conservation of biological diversity is one of the greatest challenges facing humanity today. ${ }^{1,2}$ Addressing this challenge must inevitably involve the maintenance of the composition, structure and functioning of multi-species ecosystems. ${ }^{2-4}$ While preventing the loss of particular species is an obvious strategy, a second goal might be to manage for local species diversity and the heterogeneity of habitats. ${ }^{5} \mathrm{~A}$ further objective may be the restoration of damaged ecosystems. ${ }^{6}$ Large herbivore assemblages form an important component of many diverse ecosystems and are of distinct ecological, and hence conservation, value..$^{7-9}$ On the other hand, herbivores managed at unnaturally high densities may drive detrimental changes in the structural heterogeneity of habitats. ${ }^{10-12}$ Thus, decision-makers are faced with the challenge of balancing the needs of populations of large herbivores with the preservation of vegetation and ecosystem diversity. ${ }^{9}$ In light of these considerations, conclusions as to whether large herbivores are 'good' or 'bad' for biological diversity are both contentious and elusive. Nonetheless, we seek to explore this question with particular reference to African savannah elephants (Loxodonta africana). We discuss whether or not the elephant should be considered a biodiversity thief - a species that upsets the natural diversity of life in the habitat in which it lives.

The African elephant has been driven to local extinction over much of its former range, with hunting for meat and ivory and the conversion of elephant habitat to agriculture constituting the major drivers. ${ }^{5}$ Given the historical decline in elephant numbers, the conservation of this species appears to be a sensible objective. ${ }^{9,13}$ However, the protection afforded to elephants in confined (usually fenced) reserves across Africa has distinct implications for the management of local species diversity and the heterogeneity of habitats. ${ }^{14,15}$ Elephants have been shown to have clear impacts on the structure of vegetation, particularly in woodland habitats ${ }^{12,16,17}$, and these changes may have knock-on effects for sympatric species ${ }^{10,18,19}$. The effects of elephants on biological diversity in protected areas are of particular concern in light of how expansion in human populations, and the land-use change that follows, places increasing pressure on reserves to preserve biological diversity., 90

Change within ecosystems is natural and inevitable and large herbivores have been living in an ever-changing environment for millions of years. ${ }^{20}$ Changes brought on by elephants, therefore, should not automatically be categorised as undesirable, and short-term changes may be part of an overarching trend of long-term stability. 8,21 Furthermore, current elephant impacts can only be adequately assessed in the light of historical (on the scale of centuries) benchmarks, for which accurate information is notoriously scant. ${ }^{10,21}$ The current impacts of elephant populations on vegetation dynamics in some regions may in fact represent a shift towards a more natural historical state. ${ }^{8,21}$ Finally, much of the detrimental impacts of elephants on habitat structure and diversity, particularly at smaller scales, has resulted from human interventions (such as the erection of fences and the establishment of artificial water points) that have unnaturally confined elephants to localised areas, disrupted seasonal movements and disturbed the natural dynamics of population processes. .,13,22 $^{2}$

\section{The context of historical change}

The demonstrated changes in woodland and riparian forest habitats in northern Botswana, supposedly driven by an expanding elephant population, have raised a considerable amount of concern amongst ecologists in recent years. ${ }^{17,23-25}$ Seminal research in northern Botswana's Chobe river ecosystem, while clearly validating elephant-mediated vegetation changes, nevertheless questions the interpretation of these changes as undesirable. ${ }^{8}$ The authors argue that the current state of the ecosystem could perhaps be likened to the situation before the historical decline in elephant and other herbivore numbers following excessive hunting for ivory (1800s) and the rinderpest pandemic (c. 1897). ${ }^{8}$ If current impacts, however conspicuous, are simply shifting the system back to its former state, then there is no need for concern. Moreover, Owen-Smith et al. ${ }^{26}$ stress that in Kruger National Park (KNP), the historical state of vegetation assumed its form in the absence of elephants and other large herbivores (following hunting) and hence changes in vegetation with the recovery of large herbivores are inevitable and not necessarily detrimental. Furthermore, it is difficult to disentangle the relative contribution of fire and elephants to contemporary vegetation change in KNP. ${ }^{26}$ Records of past elephant numbers and movement patterns, together with data on historical vegetation structure and composition are essential benchmarks against which contemporary change can be measured. ${ }^{8}$ Unfortunately, retracing the history of natural systems is often speculative and records from the 18th and 19th centuries lack any real detail: they consist of the writings of early hunters, archaeological faunal remains and rock paintings. , 10,27 $^{2}$

\section{The role of elephants in habitat change}

Vegetation structure and composition forms an integral component of ecological diversity and, sensu stricto, negative effects of elephants on vegetation may therefore be seen as bad for biological diversity. ${ }^{3,9}$ Of all habitat types, the impact of elephants on woodland is most obvious and forms the basis of much emotive debate. $12,13,16,17$

In KNP (South Africa), Asner and Levick ${ }^{12}$ showed that elephants were the primary agents of treefall and that rates of treefall averaged six times greater in areas accessible to elephants than in exclosures. In Tanzania's Ruaha National Park, elephants were implicated in the death of $37 \%$ and $67 \%$ of measured Acacia albidia and Commiphora ugogensis trees, respectively. ${ }^{16}$ In the Miombo woodlands of Zimbabwe, the density and cover of trees were significantly lower in elephant-impacted woodlands than in adjacent intact woodland. ${ }^{10}$ In Amboseli National Park in Kenya, a long-term series of exclusion experiments showed that elephants alone are preventing the regeneration of woodlands. ${ }^{11} \mathrm{~A}$ similar study in northern Botswana showed that elephants play an important role in reducing the extent of tree cover. ${ }^{17}$ In South Africa's Tembe Elephant Park, elephants had a clear influence 
on vegetation at the species level but had no apparent impact at the woodland community level. ${ }^{15}$

Guldemond and van Aarde ${ }^{28}$ carried out a meta-analysis of 238 studies conducted over 45 years, all of which investigated the impacts of elephants on vegetation in some way. The majority of the most commonly cited and influential studies (15 of 20) recorded negative impacts of elephants on vegetation while $53 \%$ of the remaining 218 studies also recorded negative impacts..$^{28}$ There may have been introduced bias in that the majority of the most cited papers report on negative impacts and the continual citation of these in the literature may have led to an overestimation of impacts. ${ }^{28}$ Impact was most intense in areas of high elephant density, in arid savannahs and in regions in which elephants were confined by fences. ${ }^{28}$ The analysis highlighted the difficulty of disentangling the relative contributions of climate, fire, drought, soil characteristics and herbivores to the woodland loss recorded in many of the studies - a challenge that has been emphasised elsewhere.,8,11,17

While the damaging effects on trees are clear, elephant browsing often facilitates the establishment and spread of the shrubby and herbaceous vegetation that replaces woodland, facilitating, in turn, the biological communities associated with these alternative vegetation types. ${ }^{8,10,12}$

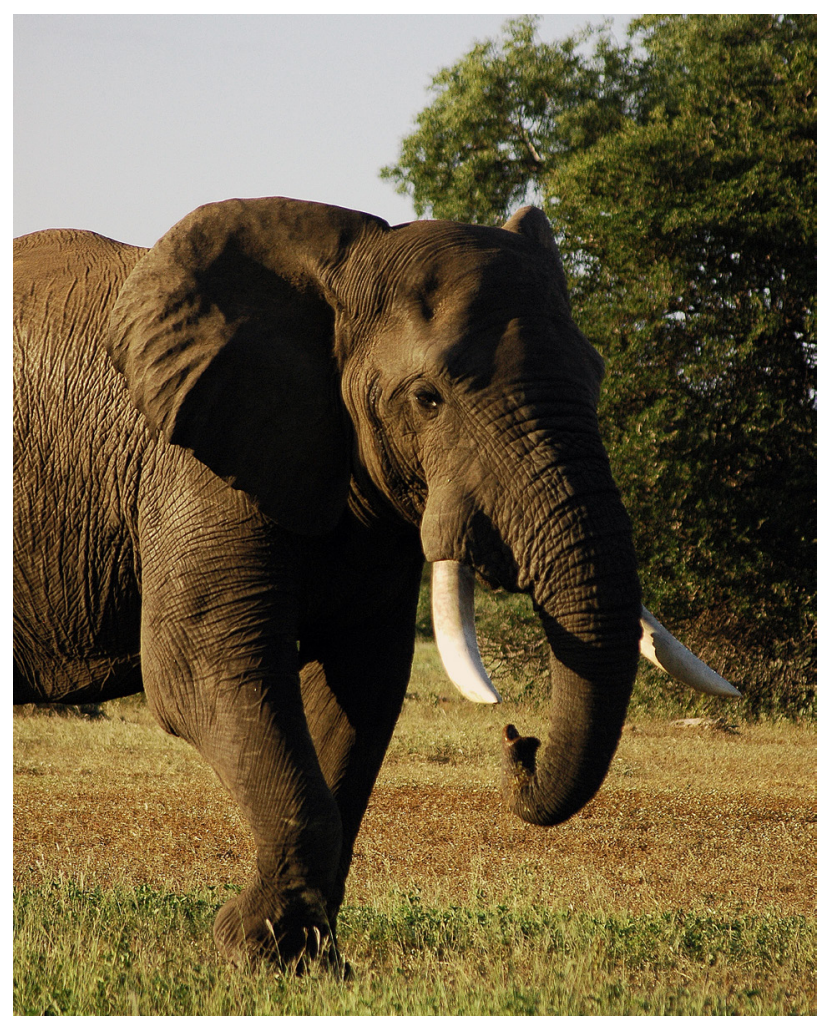

Figure 1: A bull elephant in Ntsiri Nature Reserve adjacent to Kruger National Park, South Africa. This majestic giant needs about $170 \mathrm{~kg}$ of green food a day and can be quite destructive in its feeding habits (photo: T. Kuiper).

\section{The implications for biological diversity}

With the effect of elephants on vegetation clearly demonstrated, what are the implications for biological diversity in general? One must evaluate the effects of elephant presence within the context of the role that large herbivores play in savannah systems. The absence of elephants and other large herbivores disrupts savannah ecosystems and may lead to bush encroachment and trophic cascades. ${ }^{7,29}$ Given the role played by ungulates in ecosystem functioning, most notably through top-down forcing, their extirpation from an area will lead to cascading effects. ${ }^{7,29}$

Many studies investigating the impacts of elephants on vegetation point to the implications for biological diversity in general, but few experimentally test this assertion. ${ }^{11,16,17}$ Greater woody plant structural diversity in the absence of elephants may or may not enhance the habitat available for a wide variety of other organisms beyond herbivores. ${ }^{10,12}$ In Zimbabwe's Miombo woodlands, Cumming et al. ${ }^{10}$ recorded significantly lower abundances of ants and birds in elephant-impacted woodlands compared to adjacent intact woodland. Across 30 sampling sites in the same region, Fenton et al. ${ }^{19}$ recorded significantly lower micro-bat species richness, abundance and activity at elephant-impacted sites versus intact sites. In Amboseli National Park (Kenya), structural changes in vegetation, driven primarily by elephants, have purportedly resulted in the extirpation of both lesser kudu (Tragelaphus imberbis) and bushbuck (Tragelaphus scriptus) from the region. ${ }^{18}$

After 5 years of research into the ecosystem-level effects of elephants in northern Botswana, Skarpe et al. ${ }^{8}$ concluded that they had found no ecological reason to control elephant numbers. Their results suggested neutral or even positive effects of elephant presence on other species, including small mammals and ungulates. ${ }^{8}$ Elephant impacts were shown to increase the availability of those shrub species commonly browsed by sympatric ungulate species and the distribution of half of these species exhibited a positive correlation with elephant impact. ${ }^{8}$ Despite an expanding elephant population, increases in both buffalo (Syncerus caffer) and impala (Aepyceros melampus) numbers were recorded during the study. ${ }^{8}$

In Addo Elephant National Park, South Africa, the reintroduction of apex predators (lions, Panthera leo and spotted hyaenas, Crocuta crocuta) led to the decline of small ungulate prey in an area of the park where elephant densities were high, but no such declines were recorded in an area characterised by a long history of elephant absence..$^{30}$ The authors suggested that the denser thicket of the elephant-free area provided refuge for small prey from predation by the reintroduced apex carnivores, while the fragmented thicket of the elephant-impacted area facilitated the impact of these predators on small ungulate prey. ${ }^{30}$

\section{The role of human intervention}

Fences and artificial water points alter elephant movements, thereby increasing the localised impact on vegetation. ${ }^{22,31}$ Artificial water points allow greater dry season ranging, resulting in elephants being able to exploit areas they would not usually have access to during the dry season and reducing spatial refuges for vulnerable plant species. ${ }^{22,31,32}$ Given that elephants are more faithful to dry season than wet season ranges, the dry season presence would have a more consistent impact on the landscape than would the nomadic wet season footprint..$^{31}$ Fences act as barriers to elephant movements, leading to the restriction of wet season ranges..$^{22,31}$ In addition, fences cause elephants to visit the same areas more often in the wet season, 'bunching up' against fences and causing localised vegetation impacts. ${ }^{31}$ In combination, fences and artificial water points reduce the difference between the wet and dry season ranges of elephants and lead to vegetation impacts at a localised scale that would be avoided if elephants ranged naturally and freely. ${ }^{13,31}$

\section{Conclusions}

Many studies have focused on the short-term elephant impacts on a limited number of plant species, with weak potential for inference about higher-scale vegetation change which is likely modulated by other factors such as rainfall and fires. Also, change may wrongly be interpreted as undesirable when in fact it is natural. Finally, the impact of human interventions in mediating elephant impacts has to be emphasised and explored more extensively. Beyond these considerations, it is important to appreciate the integral role that elephants play in regulating savannah dynamics and to be reminded of the fact that the decline in large herbivores across the globe in recent years poses a significant threat to ecosystem integrity.

So, are elephants good or bad for biological diversity? A sweeping and simple answer to this question is elusive, in part because of the lack of research that explicitly seeks to answer it. While there is no question that elephants have driven extensive vegetation change in some areas, the consequences of these changes for community-wide biological diversity remain somewhat unclear. Whilst scientists may perceive elephants to be biodiversity thieves, this view appears to be based primarily on intuition, 
rather than on hard science. We found little compelling evidence for adverse effects of elephants on biological diversity.

We recommend that more rigorous and longer-term (5-15 years) experiments, designed specifically to test the impacts of elephants on biodiversity, be the focus of future research. Studies that compare a variety of robust indices of community-level biological diversity between elephant-impacted and control areas across multiple sites and over broad spatial scales are necessary before any concrete patterns become evident. Until then, conservationists will do well not to cry elephant.

\section{Acknowledgements}

This commentary originated from an essay assignment, set by Dr Daniel Parker and written by Timothy Kuiper, which formed part of the Zoology Honours course at Rhodes University (2013). We are thankful to Jaap Kuiper, Martin Villet, Adrian Craig and Jessica Comly for comments on earlier drafts.

\section{References}

1. Sutherland WJ, Bardsley S, Clout M, Depledge MH, Dicks LV, Fellman L, et al. A horizon scan of global conservation issues for 2013. Trends Ecol Evol. 2012;28(1):16-22. http://dx.doi.org/10.1016/j.tree.2012.10.022

2. Brooks TM, Mittermeier RA, Da Fonseca GA, Gerlach J, Hoffmann M, Lamoreux JF, et al. Global biodiversity conservation priorities. Science. 2006;313(5783):58-61. http://dx.doi.org/10.1126/science.1127609

3. NossRF.Indicatorsformonitoring biodiversity:Ahierarchicalapproach.Conserv Biol. 1990;4(4):355-364. http://dx.doi.org/10.1111/j.1523-1739.1990. tb00309.x

4. Groom MJ, Meffe GK, Carroll CR. Principles of conservation biology. Sunderland: Sinauer Associates; 2006.

5. Whyte IJ, Van Aarde RJ, Pimm SL. Kruger's elephant population: Its size and consequences for ecosystem heterogeneity. In: Du Toit JT, Biggs H, Rodgers $\mathrm{K}$, editors. The Kruger experience: Ecology and management of savanna heterogeneity. Washington DC: Island Press; 2003. p. 332-348.

6. Hobbs RJ, Harris JA. Restoration ecology: Repairing the earth's ecosystems in the new millennium. Rest Ecol. 2001;9(2):239-246. http://dx.doi. org/10.1046/j.1526-100x.2001.009002239.x

7. Van Langevelde F, Van De Vijver CADM, Kumar L, Van De Koppel J, De Ridder N, Van Andel J, et al. Effects of fire and herbivory on the stability of savanna ecosystems. Ecology. 2003;84(2):337-350. http://dx.doi. org/10.1890/0012-9658(2003)084[0337:EOFAHO]2.0.C0;2

8. Skarpe C, Aarrestad PA, Andreassen HP, Dhillion SS, Dimakatso T, Du Toit JT, et al. The return of the giants: Ecological effects of an increasing elephant population. AMBIO. 2004;33(6):276-282.

9. Asner GP, Levick SR, Kennedy-Bowdoin T, Knapp DE, Emerson R, Jacobson $\mathrm{J}$, et al. Large-scale impacts of herbivores on the structural diversity of African savannas. Proc Natl Acad Sci USA. 2009;106(12):4947-4952. http://dx.doi. org/10.1073/pnas.0810637106

10. Cumming D, Fenton M, Rautenbach I, Taylor R, Cumming G, Cumming M, et al. Elephants, woodlands and biodiversity in southern Africa. S Afr J Sci. 1997;93(5):231-236.

11. Western D, Maitumo D. Woodland loss and restoration in a savanna park: A 20-year experiment. Afr J Ecol. 2004;42(2):111-121. http://dx.doi. org/10.1111/j.1365-2028.2004.00506.x

12. Asner GP, Levick SR. Landscape-scale effects of herbivores on treefall in African savannas. Ecol Lett. 2012;15(11):1211-1217. http://dx.doi. org/10.1111/j.1461-0248.2012.01842.x

13. Van Aarde RJ, Jackson TP. Megaparks for metapopulations: Addressing the causes of locally high elephant numbers in southern Africa. Biol Conserv. 2007;134(3):289-297. http://dx.doi.org/10.1016/j.biocon.2006.08.027
14. Leuthold W. Changes in tree populations of Tsavo East National Park, Kenya. Afr J Ecol. 1977;15(1):61-69. http://dx.doi.org/10.1111/j.1365-2028.1977. tb00379.x

15. Guldemond R, Van Aarde R. The impact of elephants on plants and their community variables in South Africa's Maputaland. Afr $\mathrm{J}$ Ecol. 2007;45(3):327-335. http://dx.doi.org/10.1111/j.1365-2028.2007.00714.x

16. Barnes R. Effects of elephant browsing on woodlands in a Tanzanian National Park: Measurements, models and management. J Appl Ecol. 1983;20(2):521-539. http://dx.doi.org/10.2307/2403524

17. Ben-Shahar R. Woodland dynamics under the influence of elephants and fire in northern Botswana. Vegetation.1996;123(2):153-163. http://dx.doi. org/10.1007/BF00118268

18. Western D, Gichohi H. Segregation effects and the impoverishment of savanna parks: The case for ecosystem viability analysis. Afr J Ecol. 1993;31(4):269281. http://dx.doi.org/10.1111/j.1365-2028.1993.tb00541.x

19. Fenton MB, Cumming DH, Rautenbach I, Cumming GS, Cumming MS, Ford $\mathrm{G}$, et al. Bats and the loss of tree canopy in African woodlands. Conserv Biol. 1998;12(2):399-407. http://dx.doi.org/10.1046/j.1523-1739.1998.96376.x

20. Lewin R. In ecology, change brings stability. Science. 1986;234:1071-1073. http://dx.doi.org/10.1126/science.234.4780.1071

21. Parker D, Bernard R. Lessons from aloes in the Thicket Biome: Reconstructing past elephant browsing to understand the present. S Afr J Sci. 2008;104(5-6):163-164.

22. O'Connor TG, Goodman PS, Clegg B. A functional hypothesis of the threat of local extirpation of woody plant species by elephant in Africa. Biol Conserv. 2007;136(3):329-345. http://dx.doi.org/10.1016/j.biocon.2006.12.014

23. Campbell AC. History of elephants in Botswana. In: Hancock P, Cantrell M, Hughes S, editors. The future of Botswana's elephants. Gaborone: Kalahari Conservation Society; 1990. p. 5-15.

24. Colegrave $R$, Lungu $E$, Muwezwa $M$. What is happening to the elephants in Botswana? Revue de Bio Matematique. 1992;30:49-55.

25. Junker J, Van Aarde RJ, Ferreira SM. Temporal trends in elephant Loxodonta africana numbers and densities in northern Botswana: Is the population really increasing? Oryx. 2008;42(01):58-65. http://dx.doi.org/10.1017/ S0030605308000756

26. Owen-Smith N, Kerley G, Page B, Slotow R, Van Aarde RJ. A scientific perspective on the management of elephants in the Kruger National Park and elsewhere. S Afr J Sci. 2006;102:389-394.

27. Bernard RTF, Parker DM. The use of archaeological and ethnographical information to supplement the historical record of the distribution of large mammalian herbivores. S Afr J Sci. 2006;102:117-119.

28. Guldemond R, Van Aarde RJ. A meta-analysis of the impact of African elephants on savanna vegetation. J Wildlife Manage. 2008;72(4):892-899. http://dx.doi.org/10.2193/2007-072

29. Pringle R, Young T, Rubenstein D, McCauley D. Herbivore-initiated interaction cascades and their modulation by productivity in an African savanna. Proc Natl Acad Sci USA. 2007;104:193-197. http://dx.doi.org/10.1073/ pnas.0609840104

30. Tambling CJ, Minnie L, Adendorff J, Kerley GIH. Elephants facilitate impact of large predators on small ungulate prey species. Basic Appl Ecol. 2013;14(8):694-701. http://dx.doi.org/10.1016/j.baae.2013.09.010

31. Loarie SR, Aarde RJV, Pimm SL. Fences and artificial water affect African savannah elephant movement patterns. Biol Conserv. 2009;142(12):30863098. http://dx.doi.org/10.1016/j.biocon.2009.08.008

32. De Beer $Y$, Van Aarde R. Do landscape heterogeneity and water distribution explain aspects of elephant home range in southern Africa's arid savannas? J Arid Environ. 2008;72(11):2017-2025. 